\title{
Proprotein convertase furin in SARS-CoV-2 and non-small cell lung cancer
}

\author{
Rafael Rosell $^{1}$, Niki Karachaliou ${ }^{2}$, Sara Fancelli ${ }^{3,4}$, Oscar Arrieta ${ }^{5}$, Giancarlo Troncone ${ }^{6}$, Peng Cao $^{7}$ \\ ${ }^{1}$ Catalan Institute of Oncology, Germans Trias i Pujol Health Sciences Institute and Hospital, Badalona, Barcelona, Spain; ${ }^{2}$ Development of \\ Oncology Clinical, R\&D, Merck KGaA Darmstadt, Germany; ${ }^{3}$ Azienda Ospedaliero Universitaria, Careggi, Firenze, Italy; ${ }^{4}$ Institut d'Investigació \\ en Ciències de la Salut Germans Trias i Pujol (IGTP), Barcelona, Spain; ${ }^{5}$ Instituto Nacional de Cancerología, Mexico City, Mexico; ${ }^{6}$ Direttore del \\ Dipartimento Universitario di Sanità Pubblica, Università degli Studi di Napoli Federico II, Napoli, Italy; ${ }^{7}$ College of Pharmacy, Nanjing University \\ of Chinese Medicine, Nanjing, China \\ Correspondence to: Rafael Rosell, MD. Catalan Institute of Oncology, Germans Trias i Pujol Health Sciences Institute and Hospital, Badalona, \\ Barcelona 08028, Spain. Email: rrosell@iconcologia.net. \\ Provenance and Peer Review: This article was commissioned by the editorial office, Translational Lung Cancer Research. The article did not undergo \\ external peer review.
}

Submitted May 08, 2020. Accepted for publication Jun 09, 2020.

doi: $10.21037 /$ tlcr-20-716

View this article at: http://dx.doi.org/10.21037/tlcr-20-716

It is recognized that angiotensin converting enzyme 2 (ACE2) is crucial for the SARS-CoV-2 viral entry mediated by spike glycoprotein $S$, and it has been cleaved by the transmembrane protease serine TMPRSS2 (1). ACE2 levels are low in the lung and bronchial branches, except in the lung alveolar epithelial type II cells $(1,2)$. The SARS-CoV-2 also binds to ACE2 in non-small cell lung cancer (NSCLC) cells, in vitro. ACE2 and TMPRSS2 mRNA levels are higher in the human Calu-3 NSCLC cell line than in normal lung cells (1). Camostat mesylate (a TMPRSS2 inhibitor) reduces SARS-2-S, but not vesicular stomatitis virus-glycoprotein (VSVG)-driven entry into the Calu-3 cells (1). Acid sphingomyelinase (ASM), which generates ceramides in response to cellular stress, is required for plasma membrane expression of hepatocyte growth factor receptor (MET) in cancer cells, but is dispensable for VSVG trafficking (3). Furin is also necessary for the SARS$\mathrm{CoV}-2-\mathrm{S}$ entry, and a virtual ligand screening of furin proteins has shown that several anticancer agents and other compounds can act as furin inhibitors (4). Co-expression of ACE2, TMPRSS2, and/or furin, occurs in healthy human lung tissues, but is low in the A549 NSCLC cell line, which poses the question whether other receptors can intervene in SARS-CoV-2 viral entry $(4,5)$. ACE2 is an interferonstimulated gene in airway cells and it has been described that SARS-CoV-2 induces interferon-driven upregulation of ACE2 (6). However, A549 cells (KRasG12Smut/MET overexpressed) do not express ACE2, even after interferon stimulation (6). Furin is the main proprotein convertase in the activation of many receptors such as MET, insulin like growth factor 1 (IGF1), and TGF- $\beta 1$, and also some viruses such as HIV-1 (7). Since folates and methotrexate have been identified as furin-like inhibitors (4), it is tempting to speculate that the SLC19A1 receptor could also participate in the SARS-CoV-2 entry process. Indeed, SLC19A1 is a major transporter of cyclic dinucleotides produced by malignant cells and bacteria, and their uptake is inhibited by folates and methotrexate (8). Furthermore, the abundance of this receptor induces stimulator of interferon genes (STING)-interferon signaling (8). Since SARS-CoV-2 infects and replicates in low ACE2 expressing human lung cancer cell lines, we hypothesize that this emergent infection could be facilitated by other receptors and signaling pathways that are also involved in NSCLC. In H1993 cell lines (KrasG12Vmut/MET overexpression), IGF1-Akt signaling phosphorylates phosphoenolpyruvate carboxykinase 1 (PKC1) with further phosphorylation of insulin-induced gene 1 and 2 (INSIG1/2), which leads to the activation of sterol regulatory element-binding proteins (SREBPs) with transcription of lypogenesis-related genes in the Golgi apparatus and tumor proliferation (9). Since INSIG1 inhibits HIV-1 (10), it is plausible that IGF1-R 


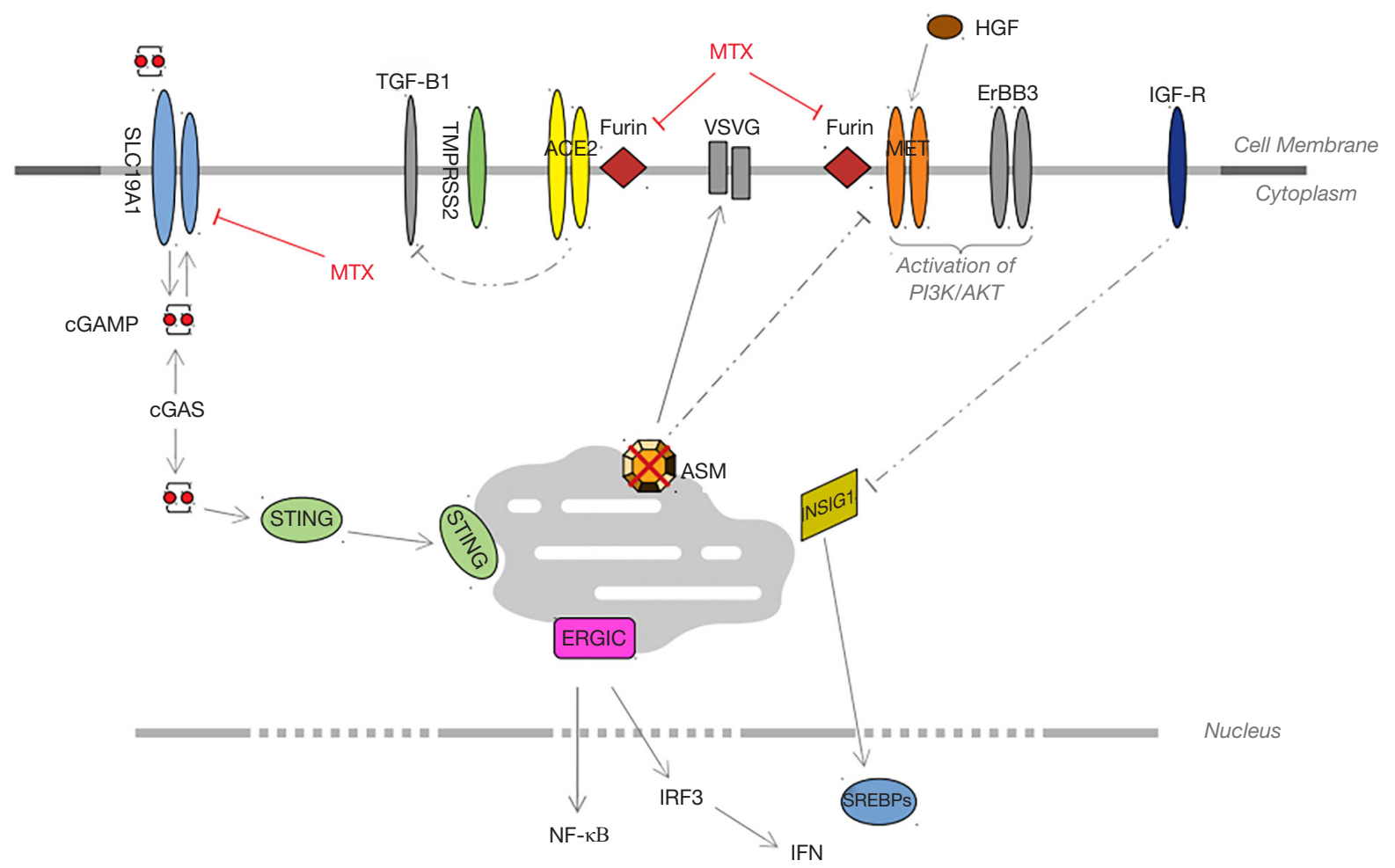

Figure 1 Mechanism for furin-promoted activation of MET in non-small cell lung cancer. ACE2, angiotensin converting enzyme 2; TMPRSS2, transmembrane protease serine 2; VSVG, vesicular stomatitis virus-glycoprotein; ASM, acid sphingomyelinase; cGAMP, cyclic guanosine monophosphate-adenosine monophosphate; cGAS, cyclic GMP-AMP synthase; TGF- $\beta 1$, transforming growth factor beta 1 ; STING, stimulator of interferon genes; ERGIC, ER-Golgi intermediate compartment; HGF, hepatocyte growth factor; MET receptor binding hepatocyte growth factor; ErBB3, receptor tyrosine kinase 3; MTX, methotrexate; IGF-R, insulin growth factor receptor; INSIG1, insulin-induced gene 1 protein; P13K/Akt, phosphatidylinositol 3'-kinase-Akt signaling; IRF3, interferon regulatory factor3; SREBPs, sterol regulatory element-binding proteins.

and MET activated by furin can cooperate with SLC19A1STING in endoplasmic reticulum-Golgi intermediate compartment (ERGIC) interferon signaling (Figure 1). In short, this new evidence opens a new perspective on NSCLC cancer patients for combination treatment with MET-Akt and furin-like inhibitors. Further research is warranted to understand the ACE2 function in NSCLC.

\section{Acknowledgments}

Funding: RR reports grants from La Caixa Foundation, and the Spanish Association Against Cancer (AECC) (PROYE18012ROSE).

\section{Footnote}

Conflicts of Interest: The authors have completed the
ICMJE uniform disclosure form (available at: http://dx.doi. org/10.21037/tlcr-20-716). RR serves as an unpaid Editorin-Chief of Translational Lung Cancer Research from June 2019 to May 2022. OA serves as an unpaid editorial board member of Translational Lung Cancer Research from Sep 2019 to Sep 2021. The other authors have no conflicts of interest to declare.

Ethical Statement: The authors are accountable for all aspects of the work in ensuring that questions related to the accuracy or integrity of any part of the work are appropriately investigated and resolved.

Open Access Statement: This is an Open Access article distributed in accordance with the Creative Commons Attribution-NonCommercial-NoDerivs 4.0 International License (CC BY-NC-ND 4.0), which permits the non- 
commercial replication and distribution of the article with the strict proviso that no changes or edits are made and the original work is properly cited (including links to both the formal publication through the relevant DOI and the license). See: https://creativecommons.org/licenses/by-nc-nd/4.0/.

\section{References}

1. Hoffmann M, Kleine-Weber H, Schroeder S, et al. SARSCoV-2 Cell Entry Depends on ACE2 and TMPRSS2 and Is Blocked by a Clinically Proven Protease Inhibitor. Cell 2020;181:271-80.e8.

2. Lukassen S, Chua RL, Trefzer T, et al. SARS-CoV-2 receptor ACE2 and TMPRSS2 are primarily expressed in bronchial transient secretory cells. EMBO J 2020;39:e105114.

3. Zhu L, Xiong X, Kim Y, et al. Acid sphingomyelinase is required for cell surface presentation of Met receptor tyrosine kinase in cancer cells. J Cell Sci 2016;129:4238-51.

4. Wu C, Yang Y, Liu Y, et al. Furin, a potential therapeutic target for COVID-19. Available online: http://chinaxiv.

Cite this article as: Rosell R, Karachaliou N, Fancelli S, Arrieta O, Troncone G, Cao P. Proprotein convertase furin in SARS-CoV-2 and non-small cell lung cancer. Transl Lung Cancer Res 2020;9(4):945-947. doi: 10.21037/tlcr-20-716 org/abs/202002.00062

5. Li H, Liu L, Zhang D, et al. SARS-CoV-2 and viral sepsis: observations and hypotheses. Lancet 2020;395:1517-20.

6. Ziegler CGK, Allon SJ, Nyquist SK, et al. SARS-CoV-2 Receptor ACE2 Is an Interferon-Stimulated Gene in Human Airway Epithelial Cells and Is Detected in Specific Cell Subsets across Tissues. Cell 2020;181:1016-35.e19.

7. He Z, Thorrez L, Siegfried G, et al. The proprotein convertase furin is a pro-oncogenic driver in KRAS and BRAF driven colorectal cancer. Oncogene 2020;39:3571-87.

8. Luteijn RD, Zaver SA, Gowen BG, et al. SLC19A1 transports immunoreactive cyclic dinucleotides. Nature 2019;573:434-8.

9. Xu D, Wang $Z$, Yan $X$, et al. The gluconeogenic enzyme PCK1 phosphorylates INSIG1/2 for lipogenesis. Nature 2020;580:530-5.

10. Zhang Y, Lu J, Ma J, et al. Insulin-induced gene 1 (INSIG1) inhibits HIV-1 production by degrading Gag via activity of the ubiquitin ligase TRC8. J Biol Chem 2019;294:2046-59. 